\title{
Prospects for Improving the Technology of Post-harvest Grain and Seed Processing and Technical Means to Implement it
}

\author{
Vladimir I. Orobinsky, Alexey M. Gievsky, and Vyacheslav A. Gulevsky* \\ Voronezh State Agrarian University named after Emperor Peter the Great, Voronezh, 394087, Russia
}

\begin{abstract}
The paper presents the data of long-term research on the composition of harvested mass coming for post-harvest processing from grain harvesters, outlines possible ways to improve the technology of postharvest grain and seed processing. It proposes a number of engineering solutions and describes grain separators for sorting and grading all types of grain. A secondary aspiration channel with a double grain cleaning capacity and an installed pendulum valve was developed, providing high-quality cleaning of grain heaps in all types of processing and increases the sorting of biologically defective grain up to $20 \%$. Some solutions are proposed to reduce air and energy consumption by $20-30 \%$ by mounting a sieve boot onto a corrugated elastic pneumatic cylinder and sequential use of air flow in a fractional separator for secondary cleaning of seeds, as well as a fundamentally new scheme of machines servicing air.
\end{abstract}

\section{Introduction}

The target program of the Ministry of Agriculture of the Russian Federation on "Improving the quality of staff for the farming industry of the Russian Federation" provides for the establishment and development of innovative educational, scientific and industrial divisions at agricultural universities (training and production sites, scientific testing and problem laboratories, industry business incubators, agricultural technology parks and others), promoting the quality of training the staff for the farming industry.

Innovative educational, scientific and industrial divisions will ensure a systematic change of generations of research and academic personnel avoiding losses in the quality of activities they are engaged in, increasing the practical focus and quality of personnel trained for the farming industry. It is the personnel who bear innovative knowledge, skills and abilities, and will ensure the effective integration of innovative technologies as an essential element in the development of the national farming industry.

Encouraging students and postgraduates to participate together with research and academic staff of the university in the activities proposed by any of these divisions will provide in-depth knowledge and implementation tools of resource-saving technologies for agricultural production, experience of implementating them in production and prospects for further improvement. Apparently, the most important thing is that this will help develop the analytical thinking of young experts, involve them in solving the most important national economic tasks. Only personnel who haev innovative knowledge will ensure the integration of innovative technologies to foster agricultural production and technical implementation tools.
One of these challenges is obtaining high-quality seeds and food grains, which will advance productivity and competitiveness of commercial grain in the grain market. It is precisely because of the low quality that agricultural producers are often forced to sell grain as fodder, without receiving funds they need for efficient production.

Seed preparation is a particularly relevant issue. The loss of harvest due to unsatisfactory preparation reaches $10-15 \mathrm{mln}$ tons in the country on average.

In order to reduce grain damage during its postharvest processing, it should pass through a minimum number of machines and transporting devices. Therefore, when developing new grain cleaning machines and grain cleaning units, it is necessary to reduce the number of operations and shorten the duration of in-process opeartions. The level of damage to seeds and marketable grain during post-harvest processing depends on configurations of grain cleaning equipment, their technological parameters, and the length of operations. Multiple collisions of grain with working and technological transporting components increase the level of damage to seeds and deteriorate their sowing qualities [1-3].

\section{Materials and methods}

Harvested mass arriving for post-harvest processing, even given a high yield, contains up to 15-20\% of biologically defective grain, as well as damaged grain and weeds that are a favorable environment for microorganisms that worsen the sowing and commercial qualities of grain while in storage [4-7].

The quality of harvested winter wheat mass arriving for post-harvest processing suggests that grains being separated

\footnotetext{
* Corresponding author: gulevsky_va@inbox.ru
} 
on the sorting sieves with holes up to $2.4-2.6 \mathrm{~mm}$ in size have a higher level of damage. It is more vulnerable to microorganisms, even when harvested mass is stored for a short time. What is more, the weight of 1,000 grains does not exceed $35.9 \mathrm{~g}$, and the laboratory germination of seeds does not meet the requirements of GOST. Numerous studies show that laboratory germination of seeds less than $2.6 \mathrm{~mm}$ in size varies within 72.1-89.0\%. Marketable quality of such grain is also low, which reduces its competitiveness in the product market. Hence, in order to obtain high-quality grain, at the earliest stage of post-harvest processing of grain heaps it is necessary to separate stock (seed or food) and fodder grains, as well as waste [6-10].

\section{Results}

The research team of the Department of Agricultural Machines, Tractors and Cars of Voronezh State Agrarian University named after Emperor Peter the Great proposed a method for cleaning and sorting of grain at the earliest stage of its post-harvest processing, protected by RF patent No. 2264068. Under the support of the Foundation for the Promotion of Small Forms of Enterprises in the Scientific and Technical Sphere, a family of grain cleaners of the OZF series was developed: OZF-50/25/10 and OZF-80/40/20, respectively, with a capacity of 50 and $80 \mathrm{t} / \mathrm{h}$ with a preliminary, 25 and $40 \mathrm{t} / \mathrm{h}$ at the primary, 10 and $20 \mathrm{t} / \mathrm{h}$ at the secondary cleaning of the grain heap. With the financial support of the Ministry of Agriculture of the Russian Federation, a separator for secondary grain cleaning SVS-30 was developed. The design of the new generation machines of the OZF family and the SVS-30 separator are shown in Fig. 1.

Technical characteristics of grain cleaners of the OZF family are given in Table 1 .

Table 1. Basic technical characteristics of OZF separators

\begin{tabular}{|c|c|c|c|}
\hline No. & Index & \multicolumn{2}{c|}{ Brand } \\
\cline { 3 - 4 } & & OZF-50 & OZF-80 \\
\hline 1 & Wheat processing capacity, $t / h:$ & & \\
& - for pre-cleaning; & 50 & 80 \\
& - for primary cleaning; & 25 & 40 \\
& - for secondary cleaning & 10 & 20 \\
\hline 2 & Electric motor power, $k W:$ & & \\
& - aspiration fan drive and augers; & 11 & 11 \\
& - drive of sieve boots & 3 & 3 \\
\hline 3 & Rotational speed of the electric & & \\
& motor, min ${ }^{-1}:$ & 970 & 970 \\
& - aspiration fan drive and augers; & 945 & 945 \\
& - drive of sieve boots & & \\
\hline 4 & Overall dimensions, $m m:$ & & \\
& - length; & 2995 & 4000 \\
& $\quad-$ width; & 2260 & 2260 \\
& - height & 2760 & 2760 \\
\hline 5 & Weight, kg & 2300 & 2600 \\
\hline
\end{tabular}

The estimated technical characteristics of the SVS-30 secondary grain cleaning separator are presented in Table 2.
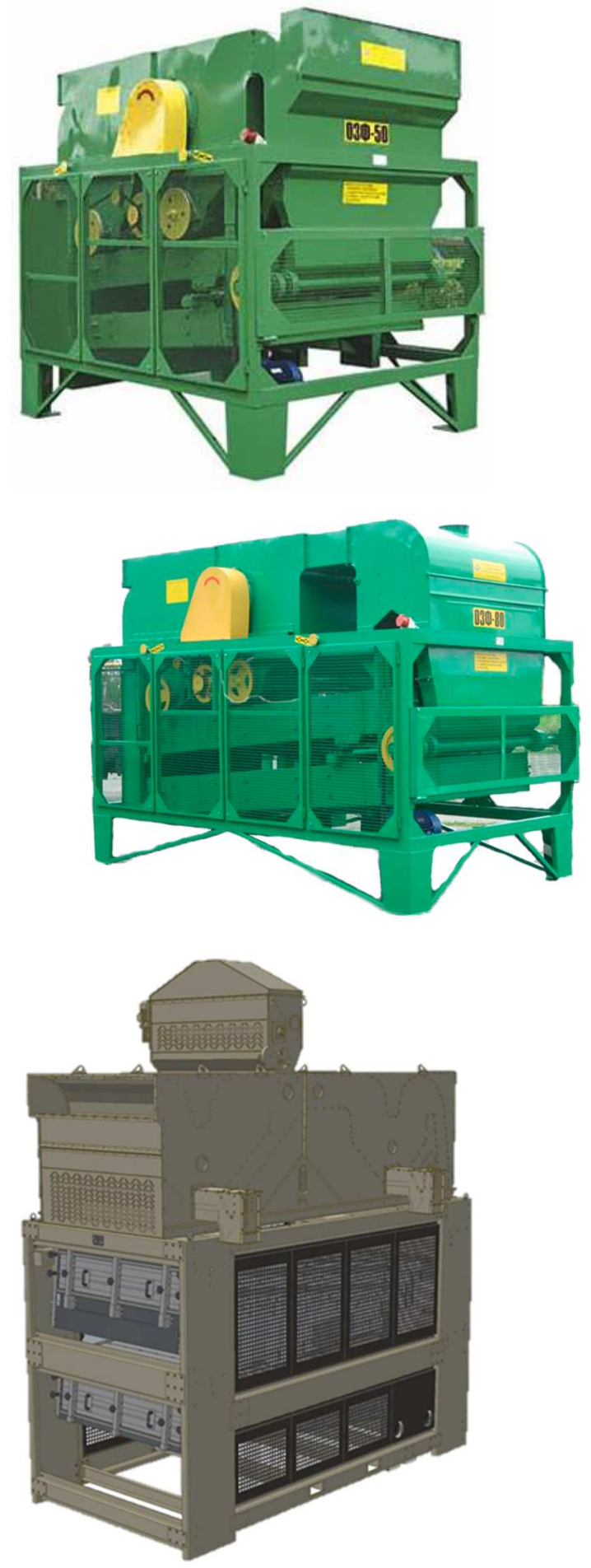

Fig. 1. Double aspiration grain cleaning machines

Table 2. Estimated technical characteristics of SVS-30

\begin{tabular}{|c|c|}
\hline Index & Value \\
\hline $\begin{array}{c}\text { Specific productivity when cleaning } \\
\text { wheat for seeds, } \mathrm{t} /(\mathrm{h} \cdot \mathrm{dm})\end{array}$ & 3.0 \\
\hline Cleaning and sorting rate, $\%$ & 85.0 \\
\hline $\begin{array}{c}\text { Total resistance of the pneumatic } \\
\text { system no more, } \mathrm{Pa}\end{array}$ & 800 \\
\hline Air consumption, thousand $\mathrm{m}^{3} /(\mathrm{h} \cdot \mathrm{dm})$ & 0.8 \\
\hline $\begin{array}{c}\text { Specific power consumption for the } \\
\text { fan drive, } \mathrm{kW} / \mathrm{dm}\end{array}$ & less than 0.5 \\
\hline $\begin{array}{c}\text { Permissible specific load on sorting } \\
\text { sieves, }[\mathrm{q}], \mathrm{kg} /\left(\mathrm{h} \cdot \mathrm{dm}^{2}\right)\end{array}$ & 37 \\
\hline
\end{tabular}


Novel engineering solutions embodied in the configuration of the OZF and SVS-30 grain cleaning machines are protected by more than thirty patents for inventions of the Russian Federation.

Prototypes of machines were tested by CC MTS for preliminary, primary and secondary cleaning of wheat seeds of the "Moskovskaya-39" variety and barley seeds of the "Gonar" variety. The results of state acceptance tests showed that machines of the OZF family provide the required cleaning quality. Based on the results of tests, they were recommended for production. Based on the results of certification tests, the machines were awarded the certificates of conformity [11].

Serial production of new generation machines of the OZF series developed by the team of scientists of the Department of Agricultural Machines, Tractors and Cars of Voronezh State Agrarian University, and manufactured by Oskolselmash LLC is organized at an enterprise in Novy Oskol, Belgorod Region. The developed scientific and technical documentation for the SVS-30 secondary seed cleaning separator was handed over to the agricultural machine building enterprise in 2020.

The machines were used for the reconstruction of existing and construction of modern grain and seed cleaning units and flows. They were presented at Russian and regional exhibitions and were awarded three gold medals and a number of diplomas.

The production trials to evaluate seed cleaning machines produced by leading foreign firms "Petkus" (Germany), "Cimbria" (Denmark), as well as the OZF family in the farms of the Voronezh, Lipetsk and Kursk regions showed that the OZF machines are not inferior to the best foreign analogues.

Once used in a fractionation mode, the OZF cleaners sort out from the harvested mass more biologically defective, crushed and damaged grains and in husk, as well as weeds, than similar machines from the "Petkus" and "Cimbria" companies [12].

Based on the test results, recommendations were prepared for experts in agricultural production "The Influence of Modern Grain Cleaning Machines and Equipment on the Quality of Seeds and the Choice of the Most Promising Options for the Development or Reconstruction of Seed Cleaning Flows", which were approved by the branch section of innovation and technical policy promoted by the scientific and technical council of the main department for agrarian policy of Voronezh region. They were published in typographic way and transferred for use to the branch services across the region. The test results are reported at regional and regional expert meetings, industrial conferences, thematic exhibitions, used within the training and retraining progremmes for staff.

During operation, the OZF machines combined wishes expressed by the manufacturers to improve their design.

Since 2007, VSAU creative team that developed a new generation of the OZF machines has been involved in a series of laboratory studies to find ways to further improve the design of machines. Reinforced with a double aspiration system including a cross-flow fan, made as per patent No. 2298441, the OZF machines are able to provide independent regulation of air flow rate in primary and secondary aspiration channels. This engineering solution is innovative in as much as the air flow rate of $4.0-6.0 \mathrm{~m} / \mathrm{s}$ can be set for wheat in the primary aspiration channel - to discharge only light weeds and of $8.0-11.5 \mathrm{~m} / \mathrm{s}-$ in the secondary aspiration channel to discharge the discarded, crushed and biologically defective grain into a fodder fraction, thereby using a frequency converter for changing the fan speed and special control ports in the aspiration channels.

Using a new sieve boot (patents No. 43798, No. 63715) with a different two-tier sieve arrangement provides an increase in the area of sorting sieves by 1.5-2.0 times with the same total area. This new engineering solution can significantly increase the productivity of fractional separators, ensure complete sorting out of discarded, crushed and biologically defective grain, to reduce energy consumption by $20-40 \%$ and metal consumption of the machine by $30-70 \%$.

The secondary pneumatic separation channel with double grain cleaning and an installed pendulum valve, protected by RF patent No. 68373, provides high-quality cleaning of harvested mass in all types of processing and increasingly sorts out biologically defective grain up to $20 \%$.

The sieve boot being mounted onto a corrugated elastic pneumatic cylinder, made as per patent for invention No. 189555, diminishes harmful vibrations, their effect on the machine frame, reduces the metal consumption of the machine structure and ensures ease of adjusting the height of the sieve boot.

A consistent use of air flow in the SVS-30 fractional separator for secondary cleaning of seeds contributes to an increase in the quality indicators with an advanced completeness of separation. Moreover, the performance of the separator is improved by $1.5-1.8$ times, the total air consumption of the pneumatic system is reduced by 25-40\% in comparison with its analogues.

A fundamentally new scheme integrated into the design of machines, enabling to maintain air parts of fractional grain cleaners for pre-sieve and post-sieve aspiration with one air flow will reduce energy consumption by $40-50 \%$.

Pneumatic separation of grain (Patent No. 2457047) and a device for gravitational distribution of bulk materials (Patent No. 2404864) simplify the design of the feeding device, reduce metal consumption and damage of grain by 1.5-3.0 \% during post-harvest processing by integrating the augers.

The creative team of the Department of Agricultural Machines, Tractors and Cars of Voronezh State Agrarian University proposed a fundamentally new scheme of the seed cleaning unit (Patent No. 2551091), enabling to install high-performance grain cleaners into its production flow. Reinforcing the unit with this type of machine will significantly reduce the length of the processing flow, dramatically reduce the number of machines used, increase the productivity and the quality of seeds and commercial grain. 
The enhanced efficiency of the machines will provide the ability to process the harvested mass as soon as it arrives avoiding temporary storage on site. Meanwhile, grains are less physically damaged, less attacked by microorganisms, the sowing and commercial qualities are improved, the costs of post-harvest grain processing and seed preparation are significantly reduced. Technical documentation has been prepared for the manufacture of an upgraded version of the OZF machines.

The presence of high-performance fractional airsieve machines is likely to exclude the second air-sieve machine from the technological flow, and, accordingly, the transporting bodies for its maintenance. The design of seed cleaning lines should be based on the principle of minimum impact on the grain during its processing.

\section{Conclusion}

Within the proposed educational, scientific and industrial division, a research team made up of students, masters and postgraduates will conduct comprehensive research to find fundamentally new highly effective engineering solutions, develop and launch them into production with the involvement of industrial enterprises in the region, implement them in agricultural production, participate in commissioning, production trials and training of employees of the enterprise for the effective use of technologies developed. Besides this, on the one hand, it will provide training of personnel - carriers of innovative knowledge that meet the requirements of innovative development of the agricultural sector in Russia, participation in the creation and organization of production of innovative engineering solutions at industrial enterprises, and on the other hand, broad participation directly in the implementation of agricultural production. Such organization of training of innovative personnel and implementation of innovative products will increase the quality and practical significance of training qualified staff, with further steady employment, for the agricultural sector of Russia.

During implementation of innovative products in the agricultural sector, it is reasonable to create branches of departments in production, which will improve the quality of student internships, the innovative focus of training the enterprise personnel, i.e. the formation of a generation of the new rural literate, committed to integrate innovative technologies and technical tools in agricultural production, as a mainspring and provider of sustainable development of rural areas, obtaining a largescale economic output through increasing the competitiveness of domestic products, effective development of the agricultural sector of the Russian economy.

A promising version of a universal grain and seed cleaning unit has been developed, protected by a patent of the Russian Federation. At present, laboratory studies are being carried out to justify the design of promising engineering solutions and their parameters for completing a modern seed cleaning unit. It is necessary to develop technical documentation for the proposed version of the universal unit, implement it in production conditions and conduct economic, and, subsequently, acceptance and certification tests with the participation of MTS.

According to the authors, a problem laboratory set up to spur the development of innovative technologies for post-harvest processing of grain and seeds and technical tolls for their implementation will accelerate the process of integrating the latest achievements into agricultural production of the Russian Federation.

\section{References}

1. V.E. Saitov, R.F. Kurbanov, A.N. Suvorov, Assessing the adequacy of mathematical models of light impurity fractionation in sedimentary chambers of grain cleaning machines, Proc. Engin., 150, 107110 (2016)

2. N.I. Kosilov, V.N Uraykin, Influence of circulation loads on the quality of work of threshing and separating devices of combine harvesters, Works of the Chelyabinsk IMESH, 95, 22-41 (1975)

3. K.D. Astanakulov, Y.Z. Karimov, G. Fozilov, Design of a grain cleaning machine for small farms, Ama-Agricult, Mehanizat. in Asia, Africa and Latin Amer., 42(4), 37-40 (2011)

4. V.E. Saitov, V.G. Farafonov, A.V. Saitov, Experimental substantiation of the effective height of a grain falling by a stream of liquid in an ergot release device, IOP Conf. Ser.: Earth Envir. Sci., 341, 012123 (2019)

5. A.P. Tarasenko, A.V. Chernyshov, D.O. Kurilov, Substantiation of basic scheme of grain cleaning machine for preparation of agricultural crops seeds, IOP Conf. Ser. Mater. Sci. and Engin., 327, 042035 (2018)

6. V.I. Orobinskiy, Improving the technology of postharvest processing of seeds by fractionation and technicak means for its implementation (Voronezh State Agrar. Univ. nam. Emp. Peter the Great, Voronezh, 2007), 334 p.

7. V.I. Orobinskiy, Reduction of grain injury during harvesting by improving the process of finalizing the ear pile in the combine thresher (Voronezh State Agrar. Univ. nam. K.D. Glinki, Voronezh, 1987), $212 \mathrm{p}$.

8. I. Badretdinov, S. Mudarisov, M. Tuktarov, E. Dick, S. Arslanbekova, Mathematical modeling of the grain material separation in the pneumatic system of the grain-cleaning machine, J. of Appl. Engin. Sci., 17(4), 529-534 (2019)

9. I.V. Baskakov, A.V. Chernyshov, Studies of the ozonation process when drying grain, IOP Conf. Ser. Earth Envir. Sci., 422, 012009 (2020)

10. A. Butovchenko, A. Dorochenko, I. Kotelnikova, Graph model development in the context of the grain cleaning machine, MATEC Web of Conf., 224, 141807 (2018)

11. F. Kalkan, M. Kara, Handling, frictional and technological properties of wheat as affected by 
moisture content and cultivar, Powder Technol., 213, 116-122 (2011)

12. A. Butovchenko, A. Doroshenko, A. Kol'Cov, V. Serdyuk, Comparative analysis of the functioning of sieve modules for grain cleaning machines, E3S Web of Conf.: Innov. Technol. in Envir. Sci. and Ed., 135, 01081 (2019) 